\title{
DEFENSIVE BEHAVIOR OF HONEY BEES TOWARD ANTS ${ }^{1}$
}

\author{
By Hayward G. Spangler and Stephen Taber, III \\ Entomology Research Division, Agr. Res. Serv., U.S.D.A. \\ Tucson, Arizona 85719
}

Honey bees (Apis mellifera L.) often exhibit a unique behavior pattern in the presence of ants. We observed this behavior pattern and obtained evidence that it is induced by odors from the ants. Although the response was not limited to odors known to be produced by ants, its primary function is probably a defense against them.

Iridomyrmex is a genus of ants commonly associated with honey bee colonies, and the Argentine ant, I. humilis (Mayr), which occurs in the southeastern United States and in California, is a frequent pest (Newell and Barber, 1913). This ant lays scent trails. No alarm pheromone has been identified from it although Blum (1969) reported that one was released by crushing the gaster. Newell and Barber (1913) and Wilson and Pavan (1959) reported that disturbed workers of $I$. humilis did not release sufficient quantities of volatile substances to be detected by human observers, but we have detected a faint odor from workers crushed between fingers. In contrast, disturbed workers of $I$. pruinosus analis (Andre) emit a strong odor which to the human observer resembles 2-heptanone, an alarm pheromone isolated from $I$. pruinosus (Roger) (Blum et al., 1963) and also from the mandibular glands of older honey bees (Shearer and Boch, 1965; Boch and Shearer, 1967).

We studied the response of bees to two species of ants to determine whether the defensive behavior of honey bees might be initiated by odorous substances and alarm pheromones from an odorous ant (1. pruinosus analis) and also by ants which were comparatively odor free (I. humilis).

\section{THE DEFENSIVE BEHAVIOR PATTERN}

Honey bees in a hive frequently were observed being approached by ants ( $I$. pruinosus analis) running about on the landing board

\footnotetext{
${ }^{1}$ This work was done in cooperation with the Arizona Agricultural Experiment Station.

Manuscript received by the editor August 3, 1970
} 
near the hive entrance. When the worker bees and ants approached each other, the bees initiated a characteristic behavior pattern that consisted initially of turning the posterior of the bees directly toward the ant. If the ant was directly ahead of the bee when detected, the rotation of the bee often approached $180^{\circ}$. During or immediately following this rotation, the bee fanned its wings vigorously. Also, simultaneously with the completion of rotation, the bee frequently kicked its hind legs rearward so they often struck the ant. The kicking action combined with air currents from the fanning wings often dislodged and moved the ant. This behavior pattern, repeated successively by a number of bees, effectively prevented the ants from entering the colony. Ants placed inside a bee colony on top of the brood comb frames were ordinarily removed from the colony in less than one hour. There was no evidence of the venom fanning behavior described by Maschwitz (1964).

CONDITIONING AS A FACTOR IN THE DEFENSIVE BEHAVIOR PATTERN

We conducted the following tests to determine whether bees that had not had recent or any contact with ants would respond with defensive behavior to ants or to an alarm pheromone. Twelve colonies were selected and arranged into groups of two each in a bee yard at Tucson, Arizona. These colonies were not opened for three days before testing.

Combs with honey were placed in locations where large numbers of worker 1 . pruinosus analis readily crawled into them to imbibe. Then the combs with the adhering ants were inserted in the brood nest in one of each group of two test hives. Three hours later, an observer who was unaware of which hives had been exposed to ants placed two $3 \times 150-\mathrm{mm}$ dowels on the tops of the brood frames in each of the 12 hives. One end of one of the dowels had been used to crush workers of $I$. pruinosus analis; the other dowel had no ant odor. The observer then counted the number of bees exhibiting defensive behavior patterns towards the dowels in each hive during a three-minute period. The entire procedure was repeated one week later, with the ants placed in the colonies that had not received them in the previous test. No defensive reactions to the control dowels were observed. A total of 379 responses to the dowels with crushed ant odor was observed in colonies previously conditioned to ants and 293 in colonies not preconditioned. When the data from both tests were lumped, the results (mean \pm standard error) indicated no significant change in the number of defense 
responses by bees that had just previously contacted ants (3r.6 $\pm 5.6)$ and those that had not $(24.4 \pm 5.4)$.

Other tests were conducted at a mountain apiary where $I$. pruinosus analis was not found. Dowels dipped $1 / 8$ inch into 2-heptanone were placed on top of the brood combs. The bees immediately responded with the defensive behavior pattern. Thus previous experience with ants was not essential for the response.

\section{COMPOUNDS RELEASING DEFENSIVE BEHAVIOR}

To determine if the bees were responding to the odors of the ants, we tested several alarm and defensive secretions of ants by the same method. The bees responded with defensive behavior to the following compounds:

Compound Ant

Benzaldehyde Veromessor pergandei

$$
\text { (Mayr) Blum et al., } 1969
$$

2-heptanone Iridomyrmex pruinosus (Roger)

Citral Acanthomyops claviger (Roger)

Formic acid Formica spp.
Blum et al., 1963

Reference

Regnier and Wilson, 1968

Wheeler, igro

Other odorous compounds not known to be present in any ant (Blum, 1969) were selected and tested in the same manner, and all tested were found to release a positive response. These compounds were as follows:

Acetic acid

Propionic acid

Acetic anhydride

Propionic anhydride

2-6 Dimethyl -4-heptanone

Propanol

Butanol

The bees also responded to both methyl and ethyl alcohols, but this response was reduced. Therefore, bees almost certainly respond to chemicals not found in ants in the same manner as they respond to those found in ants or to the ants themselves.

\section{RESPONSES TO ANTS PRODUCING HIGH-ODOR AND LOW-ODOR}

Because $I$. humilis can be a serious pest to bees and has a comparatively low level of odor to humans and because no alarm pheromones have been isolated from it, we suspected that the low odor might be the reason it can invade bee colonies with little 
resistance. The previous tests had already shown that the bees readily responded to $I$. pruinosus analis and to 2-heptanone, an alarm pheromone of $I$. pruinosus.

I. humilis workers were obtained and placed on the wooden top bars of several brood combs. The responses of the bees to these ants were reduced both in frequency and vigor from the responses to $I$. pruinosus analis; the ants generally moved freely about beneath the bees. Occasionally a bee would detect one of these ants, usually by contacting it with its antenna. The bee then went through the described behavioral response, turning its body, fanning its wings, and kicking with the rear legs. Comparatively few of the bees which detected $I$. humilis turned a full 180 degrees. When $I$. humilis workers were crushed on wooden dowels which were also laid on the tops of brood frames, some response was noted, but again it was sharply reduced.

\section{DISCUSSION}

Honey bee workers responded readily to several compounds that are not associated with ants and to several that are. This defensive behavior pattern enables the bees to rid their colony of harmful pests so the response appears to be a defense mechanism against ants. It is unlikely that the compounds tested which are not associated with ants would enter a colony under normal conditions, and strong foreign odors in a hive would frequently, if not usually, result from the presence of ants.

Bees are successful in keeping practically all small odoriferous Dolichoderine, Formicine and Myrmicine ants out of their colonies. The fact that honey bees are apparently less able to detect and respond to ants which have little demonstrable odor indicates that the odors of the ants play a key role in their detection. Therefore, Argentine ants, I. humilis, which are probably nearly odorless to honey bees, have been able to invade and damage bee colonies and often cause colonies to abscond. Were the bees able to detect these ants as readily as they detect others, they would doubtless rid their colonies of them.

Boch et al. (1970) described the behavior of honey bees exposed to 2-heptanone at the hive entrance as "short jerks forward and in reverse." Thus, 2-heptanone can apparently release more than one type of response. They also reported evidence to support previous suggestions that the primary alarm pheromones of the honey bee are associated with the sting and that 2-heptanone may be more impor- 
tant in some other function. Simpson (1966) reported that the mandibular gland secretion repelled honey bees when it was added to a dish of sucrose syrup. This repellency probably depends on the content of 2-heptanone in the mandibular glands (Butler, 1966).

Our study provides no evidence that the worker bees release their mandibular gland secretion when they detect ants. When the ant or odorous compound was removed, the defensive behavior stopped, and the bees resumed normal activity. This defensive response of honey bees toward ants described here may illustrate a situation where one species of insect appears to emit an alarm pheromone acting as a "Kairomone" (Brown et al., 1970) which releases defensive behavior for another species, and may also indicate that honey bees can react in several different ways to the same compound.

\section{SUMMARY}

Honey bees respond to ants and certain chemicals by turning away from the ants or chemicals, fanning the wings, and kicking the rear legs. This activity is believed to be a defense against ants invading the nest. Argentine ants are probably successful pests of bees because they apparently have a low level of odor.

\section{ACKNOWLEDGEMENTS}

We thank Dr. Murray S. Blum, University of Georgia, for supplying us with Argentine ant workers and Dr. William L. Nutting, University of Arizona, for reading the manuscript. We also thank the Arizona Commission of Agriculture and Horticulture for prompt and courteous processing of our permit to bring these worker ants into Arizona for experimental purposes.

\section{Literature Cited}

BLUM, M. S.

1969. Alarm Pheromones. Ann. Rev. Entomol. 14: 57-80.

Blum, M. S., F. Padovani, A. Curley, R. E. Hawk

1969. Benzaldehyde: defensive secretion of a harvester ant. Comp. Biochem. Physiol. 29: 461-6.

Blum, M. S., S. L. Warter, R. S. Monroe, J. C. Chidester

1963. Chemical releasers of social behaviour - I. Methyl-n-amyl ketone in Iridomyrmex pruinosus (Roger) (Formicidae: Dolichoderinae). J. Insect Physiol. 9: 881-5.

Boch, R. and D. A. SHEARER

1967. 2-heptanone and 10-hydroxy-trans-dec-2-enoic acid in the mandibular glands of worker honey bees of different ages. Z. Vergleich. Physiol. $54: 1-11$. 
Boch, R., D. A. Shearer and A. Petrasovits

1970. Efficacies of two alarm substances of the honey bee. J. Insect Physiol. 16: 17-24.

Brown, W. L., T. EISNER and R. H. WhitTAKer

1970. Allomones and kairomones: transpecific chemical messengers. BioScience 20: 21-2.

BUtLer, C. G.

1966. Mandibular gland pheromone of worker honeybees. Nature 212: 530 .

Maschwitz, U.

1964. Gefahrenalarmstoffe und Gefahrenalarmierung bei sozialen Hymenopteren. Z. Vergleich. Physiol. 47: 596-655.

NEWELL, W. and T. C. BARBER

1913. The Argentine ant. U.S.D.A. Bur. Entomol. Bull. 122, 98 p.

Regnier, F. E. and E. O. WILson

1968. The alarm-defence system of the ant Acanthomyops claviger. J. Insect Physiol. 14: 955-70.

SHEARER, D. A. and R. Boch

1965. 2-heptanone in the mandibular gland secretion of the honey-bee. Nature 206: 530.

SiMPSON, J.

1966. Repellency of the mandibular gland scent of worker honeybees. Nature 209: 531-2.

WHEELER, W. M.

1910. Ants. Their structure, development, and behavior. Columbia University Press, New York. p. 43, 181.

Wilson, E. O. and M. Pavan

1959. Glandular sources and specificity of some chemical releases of social behavior in dolichoderine ants. Pschye 66: 70-6. 

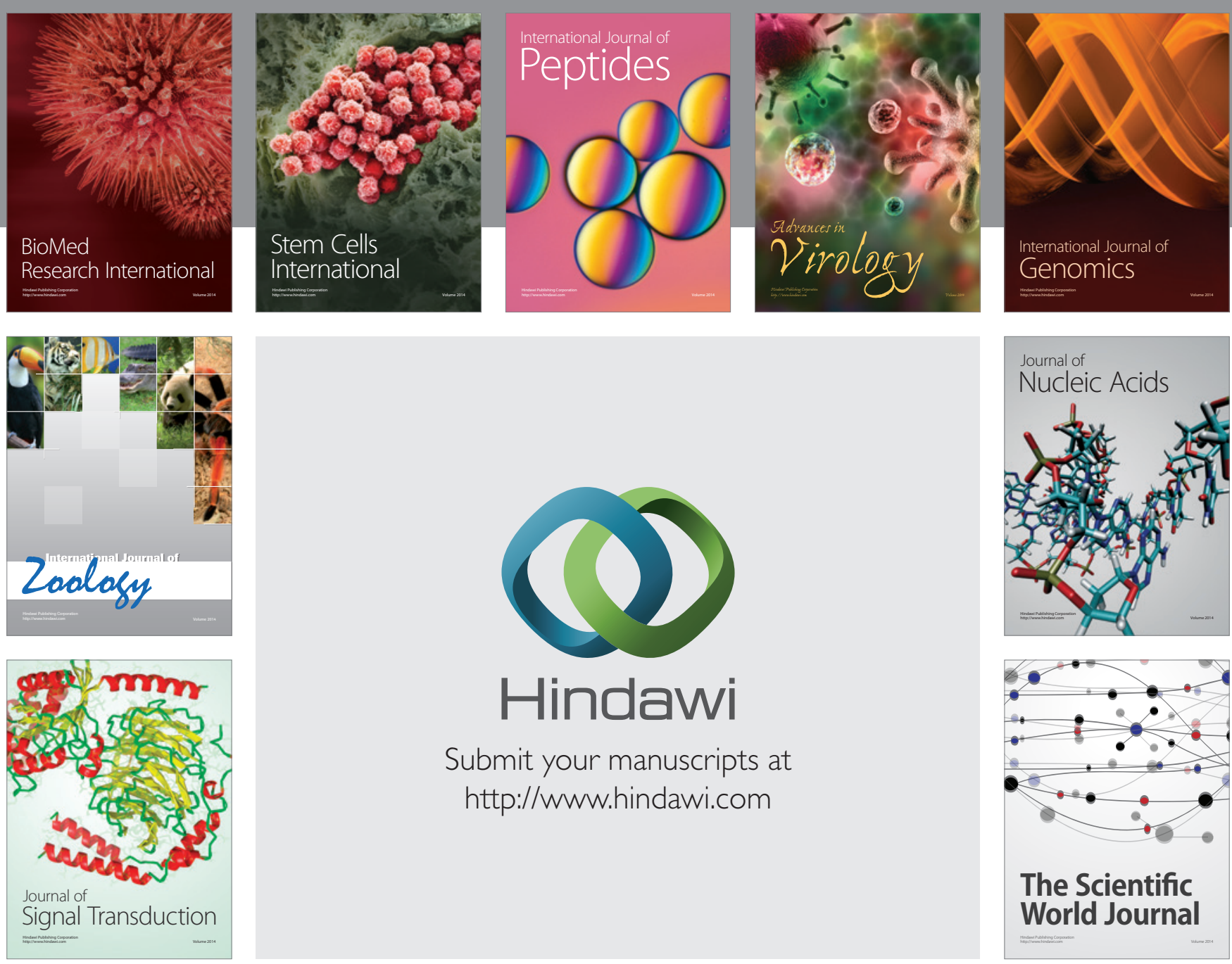

Submit your manuscripts at

http://www.hindawi.com
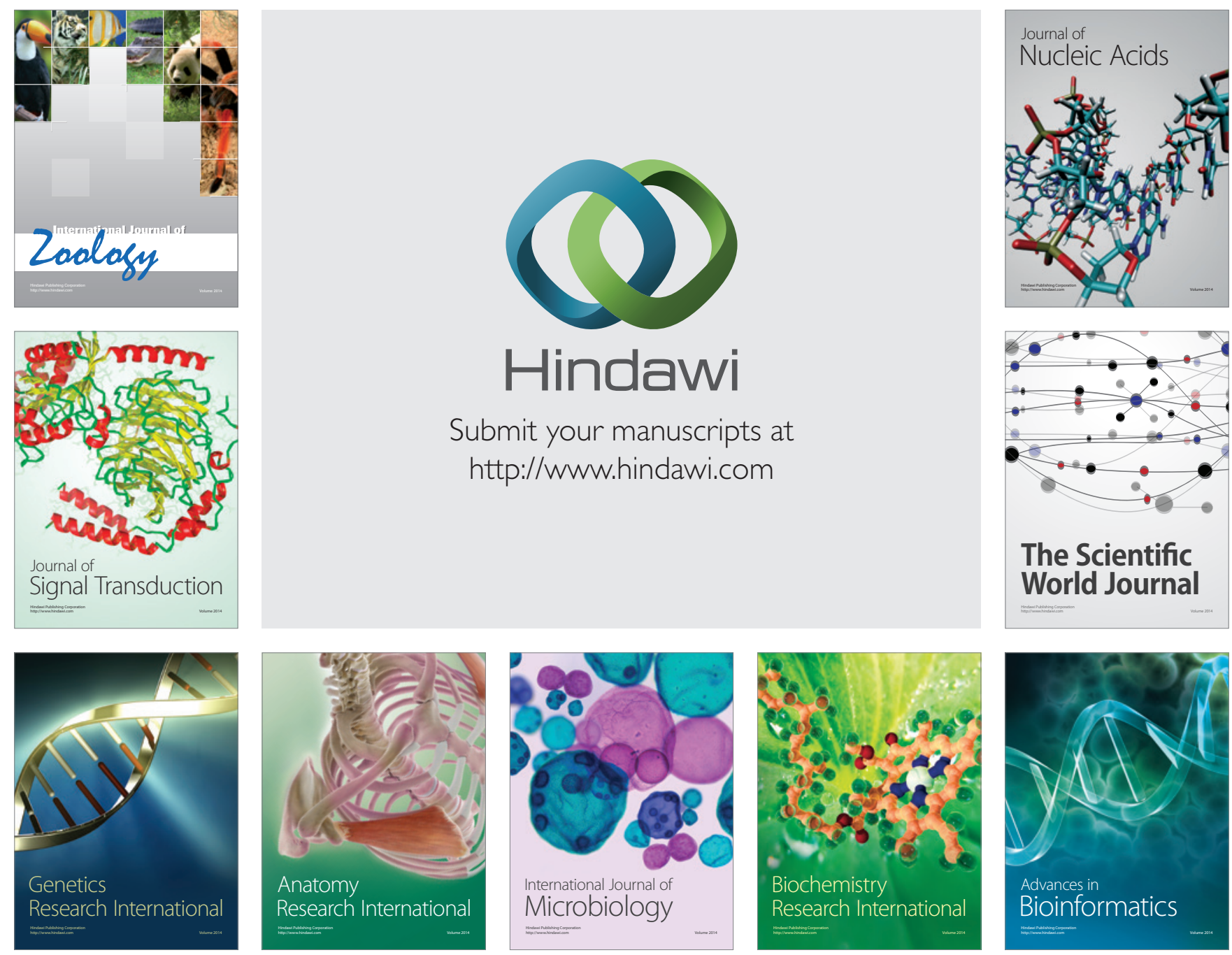

The Scientific World Journal
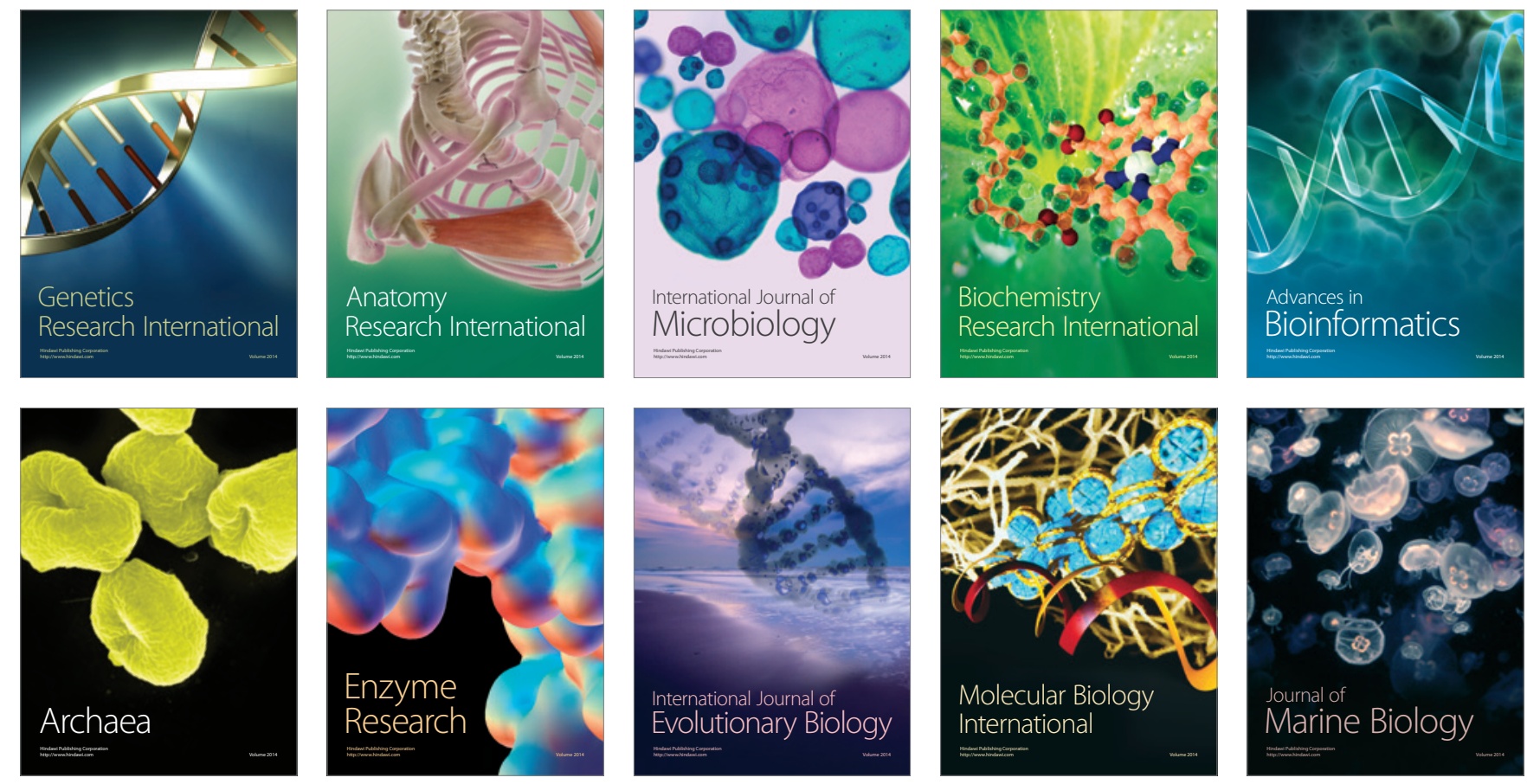